\title{
Syntactic comprehension deficits are associated with MRI white matter alterations in dementia
}

\author{
TANIA GIOVANNETTI, ${ }^{1}$ MARY W. HOPKINS, ${ }^{2}$ JACLYN CRAWFORD, ${ }^{3}$ \\ BRIANNE MAGOUIRK BETTCHER, ${ }^{1}$ KARA S. SCHMIDT, ${ }^{4}$ AND DAVID J. LIBON 4 \\ ${ }^{1}$ Department of Psychology, Temple University, Philadelphia, Pennsylvania \\ ${ }^{2}$ Department of Psychology, Mercy College, Dobbs Ferry, New York \\ ${ }^{3}$ Department of Medicine, University of Medicine and Dentistry of New Jersey-School of Osteopathic Medicine, \\ Stratford, New Jersey. \\ ${ }^{4}$ Department of Neurology, Drexel University College of Medicine, Philadelphia, Pennsylvania
}

(Received February 13, 2007; Final Revision February 27, 2008; Accepted March 3, 2008)

\begin{abstract}
Comprehension difficulties associated with periventricular and deep white matter alterations (WMA) in mild dementia were investigated using portions of the Boston Diagnostic Aphasia Examination (BDAE) Complex Ideation subtest and Syntax subtests. Mild dementia participants were grouped according to the extent of their WMA as observed on magnetic resonance imaging (mild WMA $n=45 v s$. moderate to severe WMA $n=52$ ). Correlation and regression analyses also were performed to examine the link between WMA and comprehension abilities, as well as the link between comprehension abilities and neuropsychological measures of executive functioning, language, episodic memory, and overall dementia severity. Results showed that the WMA groups differed on the BDAE-Syntax subtests, with the severe WMA group demonstrating more impairment. Correlation and regression analyses including the entire sample also demonstrated that the extent of WMA was significantly linked to Syntax test scores but not Complex Ideation scores. Regression analyses including neuropsychological measures showed that the BDAE-Complex Ideation score was marginally predicted by only overall dementia severity, whereas the BDAE-Syntax scores were significantly predicted by independent measures of working memory/executive functioning. In conclusion, greater subcortical WMA and executive deficits are associated with greater difficulties in syntactic comprehension in individuals with mild dementia. (JINS, 2008, 14, 542-551.)
\end{abstract}

Keywords: Alzheimer's disease, Vascular dementia, Subcortical dementia, Aphasia, Comprehension

\section{INTRODUCTION}

There is now considerable interest in the effect of subcortical white matter alterations (WMA) on the clinical presentation of dementia. A growing body of research has demonstrated that subcortical vascular disease results in differential impairment on a wide range of neuropsychological tests that measure concept formation, executive control and working memory, and graphomotor functioning (see Libon et al., 2004 for a review). However, language comprehension deficits have not been extensively studied in vascular dementia $(\mathrm{VaD})$ and the relation between comprehension difficulties and WMA in dementia remains

Correspondence and reprint requests to: Tania Giovannetti, Ph.D., Temple University, Department of Psychology, 1701 N. 13th Street, Philadelphia, PA 19122. E-mail: tgio@ temple.edu unknown. This paper aims to fill this gap in the current literature.

Language comprehension deficits have been widely reported in people with Alzheimer's disease (AD). Specifically, lexical comprehension difficulties have been reported most frequently and attributed to semantic knowledge degradation (Chan et al., 1995; Chertkow \& Bub, 1990; Hodges et al., 1992; Huff et al., 1988). While several authors have reported syntactic comprehension difficulties in AD (Grober \& Bang, 1995; Small et al., 1997) others have shown that syntactic comprehension, per se, is relatively preserved (Grossman et al., 1996, 1998, Grossman \& White-Devine, 1998; Rochon et al., 1994; Schwartz et al., 1979). For example, using a sentence-picture matching task, Rochon et al. (1994) have shown that comprehension abilities in AD were unaffected by syntactic complexity (see also Rochon \& Saffran, 1995; Waters et al., 1995, 1998). 
As stated, relatively few studies have examined language comprehension abilities in VaD. The handful of studies in the literature has focused on comparing comprehension abilities in participants with $\mathrm{VaD}$ to those with $\mathrm{AD}$ and/or other dementia syndromes. Theoretical papers have hypothesized greater lexical comprehension deficits in $\mathrm{AD}$ and relatively greater syntactic deficits in $\mathrm{VaD}$ (Desmond, 2004) based on neuropathology differences between $\mathrm{AD}$ and $\mathrm{VaD}$, as well as strongly held notions in the aphasia/language literature. Namely, individuals with $\mathrm{VaD}$ show differential impairment in executive functioning, and syntactical processing has been associated with working memory and prefrontal/ executive functioning, even among dementia patients (see Kempler et al., 1998). Moreover, lexical and semantic processing have been associated with declarative memory systems and the temporal cortex, and these processes are known to be differentially impaired in people with $\mathrm{AD}$ (see Friederici et al., 2003; Ullman, 2001; Ullman et al., 1997). To date, only one report supports this dissociation in $\mathrm{AD}$ and $\mathrm{VaD}$ participants (Kertesz et al., 1990); other empirical studies have demonstrated little to no differences in comprehension abilities between $\mathrm{AD}$ and $\mathrm{VaD}$ participants (Powell et al., 1988; Villardita, 1993; Vuorinen et al., 2000). Another group of studies has reported results that contradict this hypothesis (Grossman et al., 1996; Kontiola et al., 1990). For example, Grossman and colleagues (1996) showed that participants with VaD performed better than AD participants on tests of both lexical and syntactic comprehension.

One major limitation of the aforementioned $\mathrm{AD}$ versus $\mathrm{VaD}$ studies is that patients were grouped according to their clinical diagnosis. Only Kertesz and colleagues (1990) grouped participants according to WMA as observed on neuroimaging. There is accumulating evidence to suggest that the neuropathology underlying the clinical syndromes of $\mathrm{AD}$ and VaD can overlap (Jellinger, 2002; Pantoni \& Garcia, 1997; see also Libon et al., 2004, 2008; Price et al., 2005). Therefore, the grouping methods used in prior studies may have obscured meaningful differences in neuropathology across participants. To address this possibility, recent studies have demonstrated statistically significant neuropsychological differences across dementia groups that differed according to WMA observed on magnetic resonance imaging (MRI) of the brain (Libon et al., 2008; Price et al., 2005, 2007). Thus, in the current study, patients diagnosed clinically with $\mathrm{AD}$ or $\mathrm{VaD}$ were re-grouped on the basis of the severity of their WMA as measured on MRI. Furthermore, participants' WMA scores were evaluated as a continuous variable in correlation and regression analyses, along with measures of comprehension abilities.

The goal of this study was to evaluate language comprehension abilities among mild dementia participants that differed according to the extent of their MRI-WMA. Comprehension abilities were assessed using subtests of the Boston Diagnostic Aphasia Battery (BDAE): Complex Ideation (paragraph portion) and Syntax subtests (Embedded Sentences \& Touch A with B). According to the BDAE manual, the Syntax subtests specifically assess partici- pants' ability to process complex syntactical relations; the Complex Ideation subtest is described as a more elementary measure of language comprehension and is associated with other tests of lexical and semantic processing (Goodglass et al., 2001). We hypothesized that participants with greater WMA, who are known to be especially disadvantaged on neuropsychological measures of executive functioning and working memory (Lamar et al., 2007; Libon et al., 2004; Looi \& Sachdev, 1999), would experience language comprehension deficits characterized by syntactic comprehension difficulties. In contrast, dementia participants of comparable overall dementia severity but with less severe WMA are known to demonstrate greater deficits in declarative memory systems than those with moderate to severe WMA (Libon et al., 2004); therefore, we hypothesized that these participants would experience comprehension deficits secondary to lexical or semantic processing impairments. Based on these hypotheses, we predicted that dementia patients with significant WMA would demonstrate greater deficits on the BDAE-Syntactic subtests than participants with little or no WMA, whereas participants with mild WMA would demonstrate greater deficits on the BDAE-Complex Ideation subtest. Along these lines, we also predicted that performance on the BDAE-Syntax subtests would be associated with independent measures of working memory/executive functioning; performance on the BDAE-Complex Ideation subtest would be associated with independent measures of lexical and semantic processing (i.e., naming and category fluency).

\section{METHODS}

\section{Participants}

Ninety-seven outpatients with $\mathrm{AD}$ or $\mathrm{VaD}$ were recruited from the Memory Assessment Program (MAP) of the New Jersey Institute for Successful Aging, University of Medicine and Dentistry of New Jersey-School of Osteopathic Medicine. All participants were evaluated by a social worker, neurologist, and neuropsychologist. Laboratory and brain MRI studies also were obtained on all patients. Patients' diagnoses were determined during an interdisciplinary team meeting according to established criteria (Chui et al., 1992; McKhann et al., 1984). Comprehension test scores were not used to determine participants' clinical diagnoses; however, neuroimaging data were considered when making diagnostic decisions.

Forty-seven patients were diagnosed with probable AD (McKhann et al., 1984), and 50 patients were diagnosed with possible $(n=22)$ or probable $\operatorname{VaD}(n=28$; Chui et al., 1992). No patient diagnosed with VaD presented with a cortical stroke or a sudden onset/stepwise decline in cognitive functioning.

\section{MRI protocol and participant groups}

A 1.5 Tesla Siemens MRI scanner was used to obtain T1-weighted (TR-500 ms, TE-9 ms) and FLAIR(TR-8500 ms, 
TE-99 ms) images with a $5 \mathrm{~mm}$ slice thickness and $1 \mathrm{~mm}$ gap between slices. The severity of MRI-WMA was quantified using the 40-point Leukoaraiosis (LA) Scale of Junque (Junque et al., 1990). The Junque scale is similar to several other scales described in the literature (Scheltens et al., 1993; Wahlund et al., 2001; Ylikoski et al., 1993); however, one advantage of using the Junque Scale is that it offers a wider range of measurement (i.e., 0-40) that permits robust statistical analyses. More specifically, the Junque Scale entails scores for white matter alterations in five specific areas for each hemisphere: frontal centrum semiovale, parietal centrum semiovale, white matter around the frontal horns, white matter around the body of the lateral ventricles and white matter around the atrium and the occipital horns. Scores for each area range from 0 (no visible white matter alterations) to 4 (severe white matter alterations) and are summed to equal a total score with a possible range of 0 to 40 . Past studies have demonstrated high inter-rater reliability between neuroradiologists using this scale $(r=.93, p<.001$; Libon et al., 1998).

For the present study, FLAIR-weighted MRI scans for all participants were evaluated using the Junque Scale by a board-certified neuroradiologist who never met or interacted with the patient. The neuroradiologist also was blind to all clinical information, including dementia diagnosis, and neuropsychological test scores, and he did not participate in the interdisciplinary diagnosis consensus meeting.

Currently, there is no gold standard offering concrete guidelines for the operational definition of the clinical significance of MRI-WMA. Prior work from our laboratory has suggested a Junque cut score of 10 yields distinct dementia groups that differ on neuropsychological tests of executive functioning and episodic memory (Libon et al., 2004, 2008; Price et al., 2005, 2007). Based on these past reports, participants with Junque scores $<10$ were assigned to the minimal to mild white matter group (Mild WMA Group). Participants with Junque scores of 10 or greater were assigned to the Moderate to Severe WMA Group.

\section{Procedures}

The UMDNJ-SOM Institutional Review Board approved the project, and informed consent was obtained consistent with the Declaration of Helsinki. Tests of language comprehension and other neuropsychological functions were administered as part of a comprehensive clinical protocol.

\section{Assessment of comprehension}

Comprehension was evaluated using the Complex Ideation and Syntax Comprehension subtests (Embedded Sentences \& Touch A with B) from the BDAE, a comprehensive language assessment protocol (Goodglass et al., 2001). The Complex Ideation and Syntax Comprehension subtests were selected for this study because they purportedly assess different aspects of language comprehension. Statistical analyses with a standardization sample of participants with aphasia have been reported in the recent edition of the BDAE manual (Goodglass et al., 2001). These analyses have shown that the Complex Ideation subtest clusters with other measures of basic auditory comprehension, including singleword/lexical comprehension (Basic Word Discrimination, Tools Foods, etc.) and comprehension of basic commands and semantic information (Semantic Probes, Commands); Complex Ideation did not cluster with measures of syntactical comprehension, such as Embedded Sentences and Touch A with B subtests. These latter two subtests clustered together and with another measure of syntactic comprehension (i.e., Reversible Possessives).

\section{Complex ideation subtest}

For this study, only the paragraph portion of the Complex Ideation subtest was administered. This portion of the subtest requires participants to listen to a brief paragraph read aloud by the examiner and then answer 4 yes/no questions regarding the paragraph. Four different paragraphs, comprised of grammatically regular and relatively simple sentences, are presented. The yes/no questions are designed to tap the ability to extract meaning from the short passages. Our scoring system for the paragraph portion of the BDAEComplex Ideation subtest differed from that described in the BDAE manual in that we assigned 1 point for each correct answer (range $=0-16$ ). This scoring procedure was used to increase the variance for subsequent statistical analysis.

\section{BDAE-Syntax comprehension subtests}

The syntax comprehension module of the BDAE is comprised of three subsections: Touching A with B, Reversible Possessives, and Embedded Sentences. The Reversible Possessives subtest was not included in this study, because in our clinic population the large majority of patients perform at ceiling on this measure. The Touch A with B subtest requires participants to view a series of pictures depicting a person holding or touching a fork, comb, scissors, pencil, knife, and/or spoon. Participants are required to indicate which picture accurately depicts a statement read aloud by the examiner (e.g., "Which picture shows touching the spoon and the scissors"). All of the statements in this section contain the same number of words in varied orders.

The Embedded Sentences subtest contains syntactically reversible phrases and requires patients to determine which cartoon representation (out of 4 options) best depicts the events described by the stimulus statement (e.g., "Show me the picture of the boy hitting the girl who is sitting down?"). This task assesses participants' ability to appropriately link a descriptive subordinate clause to either the subject or the object. The length of each statement is limited to 7 to 10 words. Our scoring procedures for the syntax subtests did not differ from those described in the BDAE manual; one point was awarded for each correctly identified picture. 


\section{Neuropsychological Assessment}

In addition to the Mini Mental-State Examination (Folstein et al., 1975) and Geriatric Depression Scale (Yesavage, 1986), all patients were administered tests that assessed working memory/executive functioning, expressive language, and episodic memory. All measures are described in detail in Table 1.

\section{RESULTS}

\section{Demographic and Neuropsychological Characteristics of the Groups}

As shown in Table 2, the groups did not differ significantly in age, education, dementia severity/MMSE, level of depression/GDS, or the distribution of men versus women. As expected, the Mild WMA Group demonstrated a significantly lower Junque Score than the Moderate-Severe WMA Group. Additionally, as expected, the distribution of patients clinically diagnosed with $\mathrm{AD}$ versus $\mathrm{VaD}$ differed across the groups, with a significantly higher proportion of AD patients in the Mild WMA Group and a higher proportion of $\mathrm{VaD}$ patients in the Moderate-Severe WMA Group (see Table 2).

Consistent with prior studies, the WMA groups also differed neuropsychologically, with the Moderate WMA Group demonstrating significantly worse performance on tests of executive functioning (i.e., WMS-Mental Control \& FAS). By contrast, the Mild WMA Group demonstrated worse performance on the measure of episodic memory. The groups did not differ on tests of lexical processing/language (BNT \& Animal Naming).

\section{Between Group Differences on the BDAE Comprehension Subtests}

As predicted, the Moderate-Severe WMA Group obtained significantly lower scores on the two syntax subtests (i.e., Touch A with B \& Embedded Sentences) than the Mild WMA Group (see Table 3). Contrary to our prediction, however, the groups did not differ on the BDAE-Complex Ideation subtest.

It is worth noting that when the sample was divided according to clinical diagnosis, a significant difference was observed for both Syntax Comprehension Subtests (Touching A with B $t=4.16, p<.01$; Embedded Sentences $t=$ 4.4, $p<.01$ ); participants with AD obtained better scores on both tests. The clinical groups did not differ on the Complex Ideation subtest $(t=.70, p>.05)$.

\section{Relations among Comprehension Measures}

Before examining the neuropsychological correlates of comprehension performance, correlations among the comprehension subtests were performed to determine whether these measures were assessing similar or different constructs.
Results showed that the Complex Ideation subtest was not significantly related to either Syntax Comprehension test (Touch A with B- $r=-.02$; Embedded Sentences $-r=.05$ ). However, the two BDAE Syntax Comprehension subtests were significantly correlated $(r=.47, p<.001)$. Thus, for subsequent analyses, the Syntax Comprehension Test scores were summed and analyzed as a single measure.

\section{Relations between Comprehension Tests and Demographic and Neuropsychological Variables}

As shown in Table 4, Complex Ideation and Syntax Comprehension scores showed different patterns of correlations with demographic and neuropsychological variables. The Syntax Comprehension score was significantly and negatively related to Junque Score, with lower or worse scores on syntactic comprehension tasks in participants with greater white matter alterations. The same pattern of correlations was noted for clinical diagnosis. Correlations including all other demographic variables were weak and nonsignificant. Note that point-biserial correlations were performed to evaluate the link between dichotomous variables, such as sex and clinical diagnosis, and comprehension test scores; the $+/-$ value of the $r_{p b}$ value should not be interpreted for these analyses.

There also were significant and positive relations between working memory/executive measures and Syntax Comprehension scores. As expected, as performance on measures of working memory/executive functioning improved, scores on Syntax Comprehension tests also increased or improved. Unexpectedly, a significant negative correlation was observed between the episodic memory measures and syntax comprehension. This suggests that participants who exhibited better episodic memory performance demonstrated poorer syntax comprehension. Contrary to prediction, all correlation analyses including the Complex Ideation score were nonsignificant; only the MMSE showed a modest, but nonsignificant relation to Complex Ideation.

To assess the influence of multiple neuropsychological predictors on comprehension abilities, two multiple regression analyses were performed with Complex Ideation or Syntax Comprehension scores as the dependent variable. For both regressions, neuropsychological variables were included as predictor/independent variables; the MMSE was entered into the regression model first to account for general dementia severity, followed by the remaining test scores. The results are shown in Table 5. For the BDAE-Complex Ideation subtest, the MMSE was only marginally significant $(F=3.75, p=.057)$; all other neuropsychological measures were not significant predictors $(F=1.08, p=$ .38). For the Syntax Comprehension Tests, the MMSE was not significantly related to performance $(F=1.82, p=$ .18); however, the remaining neuropsychological variables were significant $(F=4.98, p<.01)$, with FAS, a measure of working memory/executive functioning, as the only significant predictor variable. 
Table 1. Neuropsychological Protocol

\begin{tabular}{|c|c|c|}
\hline Test & Description & References \\
\hline \multicolumn{3}{|l|}{ Working Memory/Executive Functioning } \\
\hline $\begin{array}{l}\text { Boston Revision of the Wechsler } \\
\text { Memory Scale Mental Control Subtest } \\
\text { (WMS-Mental Control) }\end{array}$ & $\begin{array}{l}\text { The accuracy of performance on three nonautomatized tasks (months backward, alphabet rhyming, } \\
\text { alphabet visualization) was calculated with the following algorithm: }[1-\text { (false positives }+ \\
\text { misses)/(\#possible correct) } \times 100 \text {; possible range }=0-100 \text {. Similar tests have been shown to activate } \\
\text { dorsolateral prefrontal regions in healthy younger adults. }\end{array}$ & $\begin{array}{l}\text { Lamar et al., 2002; } \\
\text { Wildgruber et al., } 1999\end{array}$ \\
\hline Phonemic Word List Generation (FAS) & $\begin{array}{l}\text { Participants were asked to generate as many words as possible in } 60 \text { seconds beginning with } \mathrm{F}, \mathrm{A} \text {, and } \mathrm{S} \text {, } \\
\text { excluding proper nouns. }\end{array}$ & Spreen \& Strauss, 1998 \\
\hline \multicolumn{3}{|l|}{ Lexical Processing/Language } \\
\hline Boston Naming Test & The number of pictures correctly named spontaneously without a semantic cue; possible range $=0-60$. & Kaplan et al., 1983 \\
\hline Animal Naming & The number of unique animal names generated within 60 seconds. & Goodglass et al., 2001 \\
\hline \multicolumn{3}{|l|}{ Episodic Memory } \\
\hline $\begin{array}{l}\text { Philadelphia (Repeatable) Verbal } \\
\text { Learning Test-Discriminability Index } \\
\text { (PrVLT-Discriminability) }\end{array}$ & $\begin{array}{l}\text { Participants were asked to remember a } 9 \text { word list, as on the California Verbal Learning Test (Delis et al., } \\
\text { 1987; see also Libon et al., 1996). The dependent variable was the accuracy on the delayed recognition } \\
\text { memory task (Recognition Discriminability); possible range }=0-100 \text {. Free-recall test trials were not used } \\
\text { as dependent variables because they require executive abilities, such as organizational skills and retrieval. } \\
\text { The Recognition Discriminibility index was selected because it is a relatively purer measure of episodic } \\
\text { memory encoding. }\end{array}$ & $\begin{array}{l}\text { Garrett et al., 2004; } \\
\text { Libon et al., 2005; } \\
\text { Price et al., } 2004\end{array}$ \\
\hline
\end{tabular}


Table 2. Demographic and neuropsychological data across WMA groups

\begin{tabular}{|c|c|c|c|}
\hline & $\begin{array}{l}\text { Mild WMA Group } \\
\qquad(n=45)\end{array}$ & $\begin{array}{l}\text { Moderate-Severe } \\
\text { WMA Group } \\
(n=52)\end{array}$ & Analysis \\
\hline & $\mathrm{M}(S D)$ & $\mathrm{M}(S D)$ & $t$ value \\
\hline \multicolumn{4}{|l|}{ Demographic Data } \\
\hline Age & $77.76(6.13)$ & $80.00(5.21)$ & 1.95 \\
\hline Education & $12.56(2.19)$ & $11.98(2.63)$ & 1.16 \\
\hline GDS & $3.60(3.48)$ & $4.31(4.05)$ & 0.92 \\
\hline \multirow[t]{2}{*}{ Junque Score } & $4.13(2.48)$ & $16.67(5.58)$ & $13.92 *$ \\
\hline & $n(\%)$ & $n(\%)$ & $\begin{array}{c}\text { chi } \\
\text { square value }\end{array}$ \\
\hline $\operatorname{Sex}(n, \%$ women $)$ & $32(71 \%)$ & $42(82 \%)$ & 2.41 \\
\hline \multirow{2}{*}{$\begin{array}{l}\text { Clinical Diagnosis (n, \% } \\
\text { Alzheimer's disease) }\end{array}$} & $40(89 \%)$ & $7(14 \%)$ & $54.95^{*}$ \\
\hline & $\mathrm{M}(S D)$ & $\mathrm{M}(S D)$ & $t$ value \\
\hline \multicolumn{4}{|c|}{ Neuropsychological Test Scores } \\
\hline MMSE & $22.64(2.64)$ & $21.98(3.33)$ & 1.06 \\
\hline WMS-Mental Control & $74.27(15.39)$ & $56.02(24.11)$ & $4.23 *$ \\
\hline FAS & $25.02(10.76)$ & $18.00(9.55)$ & $3.34 * *$ \\
\hline Boston Naming Test & $40.49(12.32)$ & $37.88(11.59)$ & 1.07 \\
\hline Animal Naming & $9.07(4.14)$ & $8.88(3.72)$ & 1.01 \\
\hline PrVLT Recognition Test & $67.87(11.64)$ & $78.82(11.37)$ & $4.68 *$ \\
\hline
\end{tabular}

${ }^{*} p<.001 ; * * p<.05$

MMSE = Mini-Mental State Examination; GDS $=$ Geriatric Depression Scale; BDAE $=$ Boston Diagnostic Aphasia Examination; WMS = Wechsler Adult Intelligence Scale; P(r)VLT = Philadelphia (repeatable) Verbal Learning Test.

\section{DISCUSSION}

This study assessed the influence of WMA in people with mild dementia on lexical and syntactic comprehension. As hypothesized, moderate to severe WMA were associated with worse performance on measures of syntactic comprehension. This relation was observed in both betweengroup analyses comparing participants with mild WMA to those with moderate-severe WMA, as well as correlation analyses between syntax comprehension scores and WMA (Junque) scores. Contrary to our second hypothesis, however, we did not observe a relation between WMA scores and performance on more elementary lexical comprehension abilities, as measured with the BDAE Complex Ideation subtest. Specifically, the two WMA groups did not differ on this test and the Complex Ideation score was not significantly correlated with WMA (Junque) scores.

We also predicted significant relations between specific comprehension abilities and specific measures of neuropsychological functioning. That is, we predicted a link between syntax comprehension and independent neuropsychological tests of working memory/executive functioning, and this prediction was supported by both correlation and regression analyses. However, our prediction of a link between lexical comprehension abilities (Complex Ideation) and independent measures of lexical processing was not supported.
Complex Ideation was marginally related to and predicted by only general dementia severity, as measured by the MMSE. This suggests that lexical comprehension abilities may be negatively influenced by multiple cognitive difficulties in mild dementia patients. Alternatively, it is possible that Complex Ideation was not an adequate or specific measure of lexical comprehension abilities for this population. That is, the Complex Ideation task may have incurred demands on language abilities as well as working memory and episodic memory on participants, thereby limiting our ability to obtain a pure measure of lexical comprehension.

While our conclusions regarding lexical comprehension in dementia are ambiguous, our findings regarding syntax comprehension have implications for neurocognitive models of syntactic comprehension deficits in mild dementia. For example, Grossman and colleagues $(1996,1998)$ reported a link between executive functioning and impaired syntax in dementia after observing that patients with Frontotemporal Dementia (FTD) showed greater syntax comprehension deficits than patients with AD. Moreover, Grossman et al. (1998) reported that syntax comprehension deficits in FTD were associated with reduced cerebral perfusion in the left frontal and anterior temporal lobes. Our findings suggest that the link between syntax comprehension and executive functioning is also observed in cases where executive deficits may be secondary to subcortical vascular pathology. It has been sug- 
Table 3. BDAE comprehension subtest scores across WMA groups

\begin{tabular}{|c|c|c|c|c|}
\hline & \multirow{2}{*}{$\begin{array}{l}\begin{array}{c}\text { Mild WMA } \\
\text { Group } \\
(n=45)\end{array} \\
\mathrm{M}(S D)\end{array}$} & \multirow{2}{*}{$\begin{array}{c}\begin{array}{c}\text { Moderate-Severe } \\
\text { WMA Group } \\
(n=52)\end{array} \\
\mathrm{M}(S D)\end{array}$} & \multicolumn{2}{|c|}{ Analysis } \\
\hline & & & $t$ value & Effect size $(d)$ \\
\hline Complex Ideation Subtest & $11.63(3.28)$ & $11.81(3.06)$ & 0.28 & 0.06 \\
\hline \multicolumn{5}{|c|}{ Syntactic Comprehension Subtests } \\
\hline Touching A with B & $9.38(2.32)$ & $7.88(2.51)$ & $3.02 *$ & 0.59 \\
\hline Embedded Sentences & $8.51(1.46)$ & $7.60(1.87)$ & $2.66 *$ & 0.53 \\
\hline
\end{tabular}

gested that WMA in dementia might disrupt or disconnect the downwardly projecting pathways between the dorsolateral prefrontal cortex, subcortical gray matter structures (i.e., the caudate \& thalamus), and their reciprocal projections back into the prefrontal cortex (Alexander et al., 1986; Lamar et al., 2007). Thus, disruption of prefrontal cortical processing may cause syntax deficits in dementia patients with moderate to severe WMA. The association between syntax abilities and neuropsychological measures of executive functioning supports this conclusion. Alternatively, however, the thalamus and caudate also have been associated with syntactic processing abilities (see De Witte et al., 2006; Jung et al., 2005; Nadeau \& Crosson, 1997; Radanovic \& Scaff, 2003). Therefore, an important question for future research is whether disruption of the white matter per se is directly responsible for the syntactic deficits seen in our sample, or if there is a more complex interaction between white matter alterations and their possible effect on subcortical gray matter structures.

Table 4. Correlation coefficients ( $r$ ) showing relations between comprehension measures and demographic and neuropsychological variables

\begin{tabular}{lcc}
\hline \hline & $\begin{array}{c}\text { Complex } \\
\text { Ideation } \\
\mathrm{r}\end{array}$ & $\begin{array}{c}\text { Syntax } \\
\text { Comprehension } \\
\mathrm{r}\end{array}$ \\
\hline Demographic Data & -.06 & -.01 \\
Age & .10 & -.02 \\
Education & .20 & .16 \\
MMSE & .05 & .01 \\
Geriatric Depression Scale & .01 & $-.40^{* * *}$ \\
Junque Score & .12 & .07 \\
Sex* & .08 & $.47 * * *$ \\
Clinical Diagnosis* & & $.39 * * *$ \\
Neuropsychological Measures & .08 & $.44 * * *$ \\
WMS-Mental Control & .11 & .10 \\
FAS & .14 & .17 \\
Boston Naming Test & .09 & $-.27 * *$ \\
Animal Naming & .07 & \\
P(r)VLT Recognition Test & & \\
\hline \hline
\end{tabular}

*point biserial correlations $\left(\mathrm{r}_{\mathrm{pb}}\right) ; * * p<.01 ; * * p<.001$
Another relevant question for future research is whether syntactical comprehension deficits associated with WMA are mediated by working memory limitations or are due to a specific impairment in syntactic processing. Several authors have proposed that sentence comprehension difficulties in AD may be best explained by working memory deficits rather than syntactic processing problems, per se (Kempler et al., 1998). While the current results support a link between working memory and syntactic comprehension abilities in mild dementia, semantic processing, per se, was not directly manipulated in the study. Therefore, the precise cognitive mechanism(s) that lead to syntactic comprehension problems in dementia patients with moderate to severe WMA are not fully understood.

Our decision to analyze our data according to WMA instead of diagnosis is somewhat novel. We encourage this approach for future investigations aimed at characterizing the neurocognitive deficits associated with distinct dementia syndromes for several reasons. First, neuroimaging variables may be obtained objectively by individuals blind to the participants' clinical history and presentation. This prevents circularity in studies of neurocognitive and behavioral variables, as these cognitive and behavioral features often comprise core diagnostic criteria of the diverse dementia syndromes. Second, neuroimaging variables may help to equalize study groups across laboratories and clinics. Although common research criteria are used across settings, laboratories differ considerably in terms of the depth of their participant evaluation, review of background records, and interpretation of diagnostic criteria. This diversity in methods may contribute to low reliability for diagnosing dementia sub-syndromes across laboratories (see Knopman et al., 2001). Third, recent studies have shown that participants clinically diagnosed with $\mathrm{AD}$ or $\mathrm{VaD}$ show similar or overlapping neuropathology upon autopsy (Jellinger, 2002; Pantoni \& Garcia, 1997; see also Libon et al., 2004 for a review). Thus, as compared to clinical diagnosis, neuroimaging variables may offer a more direct method of linking neuropathology to cognitive/behavioral symptoms. These points notwithstanding, we must emphasize that our analyses did not show that our measure of WMA was a superior predictor of specific language comprehension def- 
Table 5. Multiple regression analyses

\begin{tabular}{lccc}
\hline \hline Coefficients & Beta & $t$ & $p$ value \\
\hline Complex Ideation Regression & $\left(R=.28, R^{2}=.08\right)$ & \\
MMSE & 0.23 & 1.95 & 0.06 \\
WMS-Mental Control & -0.05 & -0.32 & 0.75 \\
FAS & 0.09 & 0.59 & 0.56 \\
Boston Naming Test & 0.15 & 1.14 & 0.26 \\
Animal Naming & -0.04 & -0.25 & 0.80 \\
PrVLT & 0.05 & 0.38 & 0.70 \\
Syntax Comprehension Regression $(R=.54$ & $\left.R^{2}=.29\right)$ & \\
MMSE & 0.15 & 1.30 & 0.18 \\
WMS-Mental Control & 0.22 & 1.59 & 0.12 \\
FAS & 0.41 & 3.16 & $<.01$ \\
Boston Naming Test & 0.04 & 0.36 & 0.72 \\
Animal Naming & -0.08 & -0.66 & 0.51 \\
PrVLT & -0.07 & -0.62 & 0.53 \\
\hline \hline
\end{tabular}

MMSE $=$ Mini-Mental State Examination; WMS = Wechsler Memory Scale; FAS = Verbal (Letter) Fluency; BNT = Boston Naming Test; $\mathrm{P}(\mathrm{r}) \mathrm{VLT}=$ Philadelphia (repeatable) Learning Test.

icits than clinical diagnosis. Instead, there was considerable overlap between diagnosis and WMA in this sample, and the two variables performed quite comparably in detecting differences in comprehension patterns among participants.

The results of the current study should be viewed as a preliminary clinical investigation into the comprehension deficits associated with WMA. We acknowledge several limitations. First, the Complex Ideation subtest may not have been the most appropriate measure of basic, lexical comprehension for participants with mild dementia. A more elementary measure using shorter paragraphs or sentences may have shown different results. Second, only participants clinically diagnosed with $\mathrm{AD}$ or $\mathrm{VaD}$ were included in the study. Inclusion of participants clinically diagnosed with mixed $\mathrm{AD}$ and $\mathrm{VaD}$ would have offered the opportunity to evaluate whether syntactic comprehension deficits were linked to WMA, irrespective of diagnosis. Last, we did not include neuroimaging variables reflecting the integrity of other brain structures or pathology, such as the temporal or prefrontal cortex, global cortical atrophy, and subcortical gray matter structures. Thus, we cannot be certain that the link between syntax comprehension deficits is specific to WMA; it is possible that syntax comprehension abilities are related to additional measures of cortical and/or subcortical integrity.

Despite these limitations, this study also has several strengths. First, this investigation explores a relatively understudied topic in dementia: language comprehension abilities. A specific relation between syntax comprehension and WMA was observed, which was not noted for a measure of lexical or general language comprehension (Complex Ideation). Second, to our knowledge, our study is only one of two in the current literature (see Kertesz et al., 1990) that has evaluated the direct relation between WMA, as quantified from MRI, and comprehension abilities in people with dementia. The large majority prior comprehension studies on this topic have relied exclusively upon clinical diagnosis (AD vs. $\mathrm{VaD})$ as the group variable.

In conclusion, although our findings did not support the predicted double dissociation on tests of basic paragraph and syntactic comprehension, poorer performance on syntactic tests was consistently related to greater WMA and lower performance on tests of executive control in patients with mild dementia. This finding could have important clinical implications in counseling families regarding communication strategies for dementia patients. For example, for patients with extensive WMA, conversations should be brief and direct, with important points clearly reiterated. More specifically, family members should be encouraged to use simple (i.e., subject-verb-object) sentences that reduce working memory burden. Future studies should examine the effect of these specific recommendations for patients with extensive WMA as compared to patients with comparable dementia severity and mild to no WMA.

\section{ACKNOWLEDGMENTS}

Portions of the work were presented at the 36th annual meeting of the International Neuropsychological Society, Boston, MA. The authors are grateful to Priscilla Britnell, Joel Eppig, and Christy Favinger for their help with editing an earlier draft of this manuscript.

\section{REFERENCES}

Alexander, G.E., DeLong, M.R., \& Strick, P.L. (1986). Parallel organization of functionally segregated circuits linking basal ganglia and cortex. Annual Review of Neuroscience, 9, 357-381.

Chan, A.S., Salmon, D.P., Butters, N., \& Shannon, S.A. (1995). Sementic network abnormality predicts rate of cognitive decline in patients with probable Alzheimer's disease. Journal of the International Neuropsychological Society, 1, 297-303.

Chertkow, H. \& Bub, D. (1990). Semantic memory loss in dementia of the Alzheimer's type: What do various measures measure? Brain, 113, 397-417.

Chui, H.C., Victoroff, J.I., Margolin, D., Jagust, W., Shankle, R., \& Katzman, R. (1992). Criteria for the diagnosis of ischemic vascular dementia proposed by the State of California Alzheimer's Disease Diagnostic and Treatment Centers. Neurology, 42, 473-480.

Delis, D.C., Kramer, J.H., Kaplan, E., \& Ober, B.A. (1987). The California Verbal Learning Test. New York: Psychology Corporation.

Desmond, D.W. (2004). The neuropsychology of vascular cognitive impairment: Is there a specific cognitive deficit? Journal of the Neurological Sciences, 226, 3-7.

De Witte, L., Wilssens, I., Engelboprghs, S., De Deyn, P.P., \& Marien, P. (2006). Impairment of syntax and lexical semantics in a patient with bilateral paramedian thalamic infarction. Brain and Language, 96, 69-77.

Folstein, M.F., Folstein, S.E., \& McHugh, P.R. (1975). MiniMental State: A practical method for grading the cognitive state of patients for the clinician. Journal of Psychiatric Research, 12, 189-198. 
Friederici, A.D., Ruschemeyer, S.-A., Hahne, A., \& Fiebach, C.J. (2003). The role of left inferior frontal and superior temporal cortex in sentence comprehension: Localizing syntactic and semantic processes. Cerebral Cortex, 13, 170-177.

Garrett, K.L., Price, C., Libon, D.J., Swenson, R., Penney, D.L., Cosentino, S., \& Jefferson, A.L. (2004). Verbal serial list learning among dementia patients with and without white matter changes: Neuropsychological Correlates. Journal of the International Neuropsychological Society, 10(Suppl. 1), 7-8

Goodglass, H., Kaplan, E., \& Barresi, B. (2001). The Boston Diagnostic Aphasia Examination ( $3^{\text {rd }}$ edition). Baltimore, MD: Lippincott, Williams, and Wilkins.

Grober, E. \& Bang, S. (1995). Sentence comprehension in Alzheimer's disease. Developmental Neuropsychology, 11, 95-107.

Grossman, M., D’Esposito, M., Hughes, E., Onishi, K., Biassou, N., White-Devine, T., \& Robinson, K.M. (1996). Language comprehension profiles in Alzheimer's disease, multi-infarct dementia, and frontotemporal degeneration. Neurology, 47, $183-189$.

Grossman, M., Payer, F., Onishi, K., D’Esposito, M., Morrison, D., Sadek, A., \& Alavi, A. (1998). Language comprehension and regional cerebral defects in frontotemporal degeneration and Alzheimer's disease. Neurology, 50, 157-163.

Grossman, M. \& White-Devine, T. (1998). Sentence comprehension in Alzheimer's disease. Brain and Language, 62, 186-201.

Hodges, J.R., Salmon, D.P., \& Butters, N. (1992). Semantic memory impairment in Alzheimer's disease: Failure of access or degraded knowledge. Neuropsychologia, 30, 301-314.

Huff, F.J., Mack, L., Mahlmann, J., \& Greenberg, S. (1988). A comparison of lexico-semantic impairment in left hemisphere stroke patients and Alzheimer's disease. Brain and Language, $34,262-278$.

Jellinger, K.A. (2002). Alzheimer disease and cerebrovascular pathology: An update. Journal of Neural Transmission, 109, 813-836

Jung, S., Hwan, S.-H., Kwon, S.-B., Yu, K.-H., \& Lee, B.-C. (2005). The clinioco-radiologic properties of deep small basal ganglia infarction: Lacune or small striatocapsular infarction? Journal of the Neurological Sciences, 238, 47-52.

Junque, C., Pujol, J., Vendrell, P., Bruna, O., Jodar, M., Ribas, J.C., Vinas, J., Capevila, A., \& Marti-Vilalta, J.L. (1990). Leukoaraiosis on magnetic resonance imaging and speed of mental processing. Archives of Neurology, 47, 151-156.

Kaplan, E., Goodglass, H., \& Weintraub, S. (1983). The Boston Naming Test. Philadelphia, PA: Lea and Febiger.

Kempler, D., Almor, A., Tyler, L.K., Andersen, E.S., \& MacDonald, M.C. (1998). Sentence comprehension deficits in Alzheimer's disease: A comparison of off-line $v s$. on-line sentence processing. Brain and Language, 64, 297-316.

Kertesz, A., Polk, M., \& Carr, T. (1990). Cognition and white matter changes on magnetic resonance imaging in dementia. Archives of Neurology, 47, 387-391.

Knopman, D.S., DeKosky, S.T., Cummings, J.L., Chui, H., CoreyBloom, J., Relkin, N., Small, G.W., Miller, B., \& Stevens, J.C. (2001). Practice parameter: Diagnosis of dementia (an evidencebased review). Report of the Quality Standards Subcommittee of the American Academy of Neurology. Neurology, 56, 1143-1153.

Kontiola, P., Laaksonen, R., Sulkava, R., \& Erkinjuntti, T. (1990). Pattern of language impairment is different in Alzheimer's disease and multi-infarct dementia. Brain and Language, 38, $364-383$
Lamar, M., Price, C., Davis, K., Kaplan, E., \& Libon, D. (2002). Capacity to maintain mental set in dementia. Neuropsychologia, 40, 435-445.

Lamar, M., Price, C., Libon, D.J., Schmidt, K.S., Penny, D.L., Kaplan, E. \& Heilman, K.M. (2007). Alterations in working memory as a function of leukoaraiosis in dementia. Neuropsychologia, 45, 245-254.

Libon, D.J., Bogdanoff, B., Cloud, B.S., Skalina, S., Giovannetti, T., Gitlin, H.L., \& Bonavita, J. (1998). Declarative and procedural learning, quantitative measures of the hippocampus, and subcortical white matter alterations in Alzheimer's disease and ischemic vascular dementia. Journal of Clinical and Experimental Neuropsychology, 20, 30-41.

Libon, D.J., Mattson, R.E., Glosser, G., Sands, L.P., Kaplan, E., Malamut, B.L., Swenson, R., \& Cloud, B.S. (1996). A nineword, dementia version of the California Verbal Learning Test. The Clinical Neuropsychologist, 10, 237-244.

Libon, D.J., Price, C.C., Garrett, K.D. \& Giovannetti, T. (2004). From Binswanger's disease to Leukoaraiosis: What we have learned about subcortical vascular dementia. The Clinical Neuropsychologist, 18, 83-100.

Libon, D.J., Price, C.C., Giovannetti, T., Swenson, R., Bettcher, B.M., Heilman, K.M., \& Pennisi, A. (2008). Linking MRI hyperintensities with patterns of neuropsychological impairment: Evidence for a threshold effect. Stroke, 39, 806-813.

Libon, D.J., Schmidt, K., Gallo, J., Penney, D.L., Swenson, R., Giovannetti, T., \& Miller, J.A. (2005). The prototypicality of extra-list intrusion errors produced on a serial list learning task by patients with mild dementia. Journal of the International Neuropsychological Society, 11 (Suppl. 1), 92-93.

Looi, J.C.L. \& Sachdev, P.S. (1999). Differentiation of vascular dementia from AD on neuropsychological tests. Neurology, 53,670 .

McKhann, G., Drachman, D., Folstein, M.F., Katzman, R., Price, D.S., \& Stadlan, M. (1984). Clinical diagnosis of Alzheimer's disease: report of the NINCDS-ADRDA work group under the auspices of the Department of Health and Human Services Task Force on Alzheimer's Disease. Neurology, 34, 939-944

Nadeau, S. E. \& Crosson, B. (1997). Subcortical aphasia. Brain and Language, 58, 355-402.

Pantoni, L. \& Garcia, J.H. (1997). Pathogenesis of leukoaraiosis: A review. Stroke, 28, 652-659.

Powell, A.L., Cummings, J.L., Hill, M.A., \& Benson, D.F. (1988). Speech and language alterations in multi-infarct dementia. $\mathrm{Neu}$ rology, 38, 717-719.

Price, C.C., Garrett, K.D., Jefferson, A.L., Cosentino, S., Bettcher, B.M., Giovannetti, T., Penney, D.L., Swenson, R., \& Libon, D.J. (2007). When does leukoaraiosis (LA) indicate a subcortical dementia? Comparison of LA groups to Huntington's disease on a list-learning paradigm. Presented at the 3rd biannual meeting of the International Society for Vascular Behavioural and Cognitive Disorders.

Price, C., Garrett, K.D., Libon, D.J., Swenson, R., Penney, D.L., Jefferson, A.L., \& Cosentino, S. (2004). Verbal serial list learning among dementia patients with and without white matter changes: Factor Solutions. Journal of the International Neuropsychological Society, 10(Suppl. 1), 8.

Price, C., Jefferson, A.L., Merino, J., Heilman, K., \& Libon, D.J. (2005). Towards an operational definition of the Research Criteria for Subcortical Vascular Dementia: Integrating neuroradiological and neuropsychological data. Neurology, 65, $376-382$. 
Radanovic, M. \& Scaff, M. (2003). Speech and language disturbances due to subcortical lesions. Brain and Language, 84, 337-352.

Rochon, E. \& Saffran, E. (1995). A semantic contribution to sentence comprehension impairments in Alzheimer's disease. Brain and Language, 65, 107-110.

Rochon, E., Waters, G.S., \& Caplan, D. (1994). Sentence comprehension in patients with Alzheimer's disease. Brain and Language, 46, 329-349.

Scheltens, P., Barkhof, F., Leys, D., Pruvo, J.P., Nauta, J.J., Vermersch, P., Steinling, M., \& Valk, J. (1993). A semiquantative rating scale for the assessment of signal hyperintensities on magnetic resonance imaging. Journal of the Neurological Science, 114, 7-12.

Schwartz, M.F., Marin, O., \& Saffran, E. (1979). Dissociations of language function in dementia: A case study. Brain and Language, 7, 277-306.

Small, J.A., Kemper, S., \& Lyons, K. (1997). Sentence comprehension in Alzheimer's disease: Effects of grammatical complexity, speech rate, and repetition. Psychology and Aging, 12, 3-11.

Spreen, O. \& Strauss, E. (1998). A Compendium of Neuropsychological Tests: Administration, Norms, and Commentary. New York: Oxford University Press.

Ullman, M.T. (2001). A neurocognitive perspective on language: The declarative/procedural model. Nature Review Neuroscience, 2, 717-726.

Ullman, M.T., Corkin, S., Coppola, M., Hickok, G., Growdon, J.H., Koroshetz, W.J., \& Pinker, S. (1997). A neural dissociation within language: Evidence that the mental dictionary is part of declarative memory, and that grammatical rules are processed by the procedural system. Journal of Cognitive Neuroscience, 9, 266-276.

Villardita, C. (1993). Alzheimer's disease compared with cerebrovascular dementia: Neuropsychological similarities and differences. Acta Neurologica Scandinavica, 87, 299-308.

Vuorinen, E., Laine, M., \& Rinne, J. (2000). Common pattern of language impairment in vascular dementia and in Alzheimer disease. Alzheimer Disease and Associated Disorders, 14, 81-86.

Wahlund, L.O., Barkhof, F., Fazekas, F., Bronge, L., Augustin, M., Sjögren, M., Wallin, A., Ader, H., Leys, D., Pantoni, F., Pasquier, F., Erkinjuntti, T., \& Scheltens, P. (2001). A new rating scale for age-related white matter changes applicable to MRI and CT. Stroke, 32, 1318-1322.

Waters, G., Caplan, D., \& Rochon, E. (1995). Processing capacity and sentence comprehension in patients with Alzheimer's disease. Cognitive Neuropsychology, 12, 1-30.

Waters, G., Rochon, E., \& Caplan, D. (1998). Task demands and sentence comprehension in patients with dementia of the Alzheimer's type. Brain and Language, 62, 361-397.

Wildgruber, D., Kischka, U., Ackermann, H., Klose, U., \& Grodd, W. (1999). Dynamic pattern of brain activation during sequencing of word strings evaluated by fMRI. Cognitive Brain Research, 7, 285-94.

Yesavage, J. (1986). The use of self-rating depression scales in the elderly. In L.W. Poon (Ed.), Handbook of Clinical Memory Assessment of Older Adults (pp. 213-217). Washington, DC: American Psychological Association.

Ylikoski, R., Ylikoski, A., Erkinjuntti, T., Sulkava, R., Raininko, R., \& Tilvis, R. (1993). White matter changes in healthy elderly persons correlate with attention and speed of mental processing. Archives of Neurology, 50, 818-824. 